\title{
Violent individuals: beyond the gender issue
}

\author{
Abstract \\ Issues related to the gender of violent individuals are analyzed, such as violence as an \\ inherently male phenomenon. The main differences of violent individuals that are linked to \\ their gender are discussed, as well as their main risk factors. Violence is part of the human \\ condition regardless of the subject gender.
}

Keywords: violence, violent individuals, gender, masculinity, femininity, transgender

\author{
Volume 6 Issue 4 - 2018
}

\author{
Nubia Carolina Rovelo Escoto,' José Juan \\ Villanueva Sierra ${ }^{2}$ \\ 'Faculty of Psychology, Autonomous University of Querétaro, \\ Mexico \\ ${ }^{2}$ Technological University of Matamoros, México
}

\author{
Correspondence: Nubia Carolina Rovelo Escoto, Faculty of \\ Psychology, Autonomous University of Querétaro, Cerro de las \\ Campanas S/N, 76010, Querétaro, México, Tel +52 44219212 \\ 00, Ext.6315; Email nubia.rovelo@uaq.mx \\ José Juan Villanueva Sierra, Universidad Tecnológica de \\ Matamoros, Carretera a Reynosa Km. 8.5, Col. Guadalupe \\ (Ejido), 87569 Matamoros, Tamaulipas, México, Tel 01868810 \\ 7600,Email jose.villanueva@utmatamoros.edu.mx
}

Received: February 14, 2018 | Published: August 22, 2018

\section{Introduction}

In recent years violence has taken an important place in the scientific research of law, criminology and other social sciences. Every day, there are new questions about causes, ways of prevention, especially regard aggressors and violent individuals. There is a vast literature on gender-based violence, but more studies are needed to analyze gender issues of violent individuals. Violence as a social and cultural phenomenon, has defined violent individuals as those intended to harm other human beings or living creatures, the main reasons for violent acting are related to the exert of power and control over others, obtaining economic and/or material gains, etc. However, we must consider that violent subjects are not sexless nor genderless individuals but embodies sexual characteristics. From a social and identity perspective, they are defined as men, women and a diversity of gender ${ }^{1}$ that includes transgender people, bigender, fluid gender, gender-queer, intersexual, etc. Gender is not tied to what genetics or biological sex defines; it is formed from what culture and society designate to everyone as characteristics and roles $^{2}$ that can be understood as feminine or masculine.

Masculinity has been associated in most societies and cultures with qualities such as strength, action, domination, courage, power and violence. Gender differences in violence are mainly influenced by social environment that encourages violence as a symbol of masculinity in men and discourage it as a symbol of femininity in women. ${ }^{3}$ At individual level, these differences clearly influence the construction of women, men and transgender people's identity based on the roles that normatively are given as feminine, masculine, or gender diversity. ${ }^{2}$ Gender stereotypes that perpetuate the idea that violence is an inherent condition of masculinity go back through historical periods, geographical regions, economic-political systems, and continue to appear as pseudoscientific arguments for politically correct ideologies which usually come from a moral or religious nature.

The idea that men tend to be more involved in violent acts than women persists in academic spaces, and it is still difficult to assume that women also exercise violence. While it is true that global statistics $^{4}$ show a higher prevalence of males who commit violent acts generally recognized as felonies, there are also lower percentages of women who commit violent acts compared to men. In the specific case of homicide, from data of more than 200 countries/territories.

...In the context of family and intimate partner relationships, women are considerably more at risk than men, yet 79 percent of all homicide victims globally are male. Moreover, some 95 percent of homicide perpetrators at the global level are also male; a share that is consistent across countries and regions, irrespective of the homicide typology or weapon used. ${ }^{5}$

Some studies on violence states that transgender people perpetrate couple violence, a systematic review ${ }^{6}$ finds that the prevalence of violence in transsexual, transgender and intersex couples ranges from 18 percent up to 80 percent and most of the victims are trans women and the manifestation of violence with greater incidence is the psychological or emotional type. Other studies and reports, in the same systematic review, focus on transgender people as victims of violence, especially those with a transphobia.

Psychological studies on gender differences when exerting violence agree that males are more likely to exercise instrumental violence $\mathrm{e}^{7.8}$ and this type can be expressed physically (e.g., punches, fractures) and/or sexually (e.g., rape, harassment). While women tend to exert relational violence that can be emotional (e.g., manipulation, blackmail) or psychological (e.g., threat, harassment). There are exceptions to these forms of violence, such as the mixed violence behaviors where women can be found perpetrating instrumental and relational violence, and men who commit both types of violence. There are also differences in the scope in which it is exerted. Generally, men are often violent in the public space and their victims are usually strangers, while women are often violent in the private space against relatives and acquaintances. Furthermore, it is common for them to employ relational violence, but they do not leave bodily injuries that are physically invisible.

Men usually exert violence against those who are in a situation of weakness or physical vulnerability and their victims are usually women such as couples, relatives, neighbors, companions, strangers), younger men or men with less power, minors, or seniors. Women also 
choose vulnerable people, and their victims are usually their partners, other women, minors (usually children) or seniors. ${ }^{9}$ Since masculine violence is instrumental, it is usually directed against strangers and occurs in public spaces, while women act regularly in the private sphere against victims who are familiar with. ${ }^{10}$

The most common risk factors associated with violent individuals are usually a combination of psychological factors (e.g., impulsivity, early experiences of violence, cognitive distortion of violence as a mean of conflict resolution, etc.), health factors (e.g., mental disorders, regular consumption of alcohol and drugs), social factors (e.g., social isolation, alienation) or economic factors (e.g., unemployment, poverty). We can go further and consider these factors taken together as structural violence ${ }^{11}$ that is typical of the neoliberal and global economy based in the exploitation and precariousness of large sectors of world population, but it also affects differently and specifically to each individual according to their gender, age, economic level, and other variables.

Female violence has often been explained because of mental, hormonal and/or emotional disorders that are typically attributed to women. Why do these kinds of explanations not usually occur when men are violent? It seems difficult to think that violent women can be apparently normal people acting like this for similar reasons to those that stimulate men to get power, domination, and control over others. It is important to take into account the psychological individuality factor because under the same risk factors circumstances, some individuals become violent while others are not. Individuality is a key aspect that, in certain cases, has greater importance than the subject's belonging to factors defined by sex or gender. In the end, a violent individual does not cease to be a person even if he belongs to the group of "men", "women" or "transgender", and fortunately not all men meet the prototype of violent man. Then violence as a historical, cultural, and social phenomenon, has more to do with the human condition, regardless of the sex or gender of the subject that exercises it.

\section{Conclusion}

Violence is part of the human condition and is not exclusive of sex or gender. There are differences in the way it is exerted because its causes and effects are manifested differently depending on the sex and gender of the individual who exert violence. Many questions remain about the violence exerted by transgender individuals. Related characteristics to psychological individuality and life conditions of the aggressors are often disregarded. It is problematic to explain behavior concerning to violent women, men or transgender individuals because they are continuously decontextualized and simplified by the media and even by the legal field.
It is important to visualize the differences that have pigeonholed violent individuals in certain stereotypes and prejudices which continue to be deeply rooted in society. It is necessary to promote greater objectivity and neutrality among researchers to achieve a more exhaustive analysis of the behaviors and attitudes that these individuals present to be able to treat them with more effective programs that go beyond the punitive strategies of isolation and mass incarceration.

\section{Acknowledgments}

None.

\section{Conflict of Interest}

This research was funded by the authors and we declare that there are no conflicts of interest.

\section{References}

1. Green ER, Maurer L. Teaching transgender toolkit: a facilitator's guide to increasing knowledge, decreasing prejudice \& building skills. Ithaca, New York: Planned parenthood of the Southern Finger Lakes; 2015.

2. Butler J. Bodies that matter: on the discursive limits of "Sex". New York: Routledge; 1993:7-272.

3. Butler J. Gender trouble: feminism and the subversion of identity. New York: Routledge; 1990:8-256.

4. World Health Organization. Informe sobre la situación mundial de la prevención de la violencia. Geneva, Switzerland; 2014.

5. UN Office on Drugs and Crime. Global study on homicide 2013. Trends, contexts, Data. Vienna, Austria: UNODC; 2013:5-166.

6. Rodríguez Otero LM, Carrera Fernández MV, Lameiras Fernández M, et al. Violencia en parejas transexuales, transgénero e intersexuales: una revisión bibliográfica. Saúde Soc, São Paulo. 2015;24(3):914-935.

7. Ostrosky-Solís F. Mentes asesinas. La violencia en tu cerebro. México: Ediciones Quo; 2008:9-235.

8. Sanmartín J. La mente de los violentos. PlanetadeLibros: Barcelona, España, Ariel; 2002:9-171.

9. Nicholls T, Petrila J. Gender and Psychopathy: an overview of important issues and introduction to the special issue. Behav Sci Law. 2005;23(6):729-741.

10. Weizmann-Henelius G, Viemerö V, Eronen M. The violent female perpetrator and her victim. Forensic Sci Int. 2003;133(3):197-203.

11. Zizek S. Sobre la violencia. Seis reflexiones marginales. Buenos Aires, Argentina: Paidós; 2008:9-287. 